\title{
O ensino em turmas multisseriadas e suas condições de trabalho: um olhar para as escolas do campo na região do Alto Solimões, Amazonas
}

\author{
Jarliane da Silva Ferreira ${ }^{1}$ \\ ${ }^{1}$ Universidade Federal do Amazonas - UFAM. Instituto de Natureza e Cultura (INC). Rua Primeiro de Maio, s/n, Colônia I. \\ Benjamin Constant - AM. Brasil. \\ Autor para correspondência/Author for correspondence: jarlianeferreira@yahoo.com.br
}

RESUMO. A educação escolar oferecida a populações rurais esteve historicamente atrelada à concepção de atraso e precariedade. Nessas experiências rurais, o poder público parece ter investido em ações tímidas, na tendência de deixar a educação rural como segundo ou terceiro plano, tomando por referências educacionais a educação urbana (Batista, 2003). Tal problemática é evidenciada quando analisamos a situação de muitas turmas multisseriadas existentes na região do Alto Solimões, as quais parecem refletir a concepção do fracasso e precariedade escolar, suscitando a necessidade de reversão do cenário atual. Este artigo pretende discutir a educação do campo, da floresta e das águas na região do Alto Solimões, no Amazonas e, especificamente, tratar das turmas multisseriadas e as condições de trabalho vivenciadas por professores e alunos nestes ambientes. Para isso, realizou-se um levantamento das questões consideradas problemas, por meio da aplicação de questionários, entrevistas e oficinas com as crianças. $\mathrm{O}$ estudo revelou a existência de muitas turmas multisseriadas na região que, contrariando a visão predominante, parece ser a única alternativa de acesso à educação escolar em algumas localidades distantes. Constatou-se ainda, que a estrutura e infraestrutura escolar, bem como a valorização de professores e transporte escolar são demandas imprescindíveis para a melhoria das condições educacionais. Sobretudo é o que as crianças, professores e comunitários querem: uma nova escola do campo, capaz de garantir sucesso e aprendizagem em um espaço confortável e qualificado.

Palavras-chave: Educação do campo no Alto Solimões, Turma Multisseriada, Condições de Trabalho. 


\title{
The teaching in multi-classes and their conditions of work: a look at the rural schools in the Alto Solimões Region, Amazonas
}

\begin{abstract}
School education offered to rural populations has historically been linked to the concept of backwardness and precariousness. In these rural experiences, public power seems to have invested in timid actions, tending to leave rural education as the second or third plan, taking as educational references urban education (Batista, 2003). This problem is evidenced when we analyze the situation of many multisite groups existing in the Alto Solimões region, which seem to reflect the conception of school failure and precariousness, provoking the need to reverse the current scenario. This article intends to discuss rural education, forest and water education in the Alto Solimões region of Amazonas and, specifically, to deal with multi-classes and the working conditions experienced by teachers and students in these environments. For that, a survey of the issues considered as problems was carried out, through the application of questionnaires, interviews and workshops with the children. The study revealed the existence of many multi-classes groups in the region that, contrary to the prevailing view, seems to be the only alternative to access to school education in some distant localities. It was also verified that the structure and school infrastructure, as well as the valorization of teachers and school transportation are essential demands for the improvement of educational conditions. Above all, this is what children, teachers and community members want: a new school in the countryside, capable of guaranteeing success and learning in a comfortable and qualified space.
\end{abstract}

Keywords: Rural Education in Alto Solimões Region, Multiclasses Group, Work Conditions. 


\section{La enseñanza en turmas multiseriales y sus condiciones de trabajo: una mirada para las escuelas del campo en la Región del Alto Solimões, Amazonas}

RESUMEN. La educación escolar ofrecida a las poblaciones rurales estuvo históricamente vinculada a la concepción de retraso y precariedad. En estas experiencias rurales, el poder público parece haber invertido en acciones tímidas, en la tendencia de dejar la educación rural como segundo o tercer plano, tomando por referencias educativas la educación urbana (Batista, 2003). Tal problemática es evidenciada cuando analizamos la situación de muchas clases multiserias existentes en la región del Alto Solimões, que parecen reflejar la concepción del fracaso y precariedad escolar, suscitando la necesidad de reversión del escenario actual. Este artículo pretende discutir la educación del campo, del bosque y de las aguas en la región del Alto Solimões, en el Amazonas y, específicamente, tratar de las clases multiseriales y las condiciones de trabajo vivenciadas por profesores y alumnos en estos ambientes. Para ello, se realizaron un levantamiento de las cuestiones consideradas problemas, por medio de la aplicación de cuestionarios, entrevistas y talleres con los niños. El estudio reveló la existencia de muchas clases multiseriales en la región que, contrariando la visión predominante, parece ser la única alternativa de acceso a la educación escolar en algunas localidades distantes. Se constató también que la estructura e infraestructura escolar, así como la valorización de profesores y transporte escolar son demandas imprescindibles para la mejora de las condiciones educativas. Sobre todo es lo que los niños, profesores y comunitarios quieren: una nueva escuela del campo, capaz de garantizar éxito y aprendizaje en un espacio cómodo y calificado.

Palabras clave: Educación del Campo en el Alto Solimões, Clases Multiseriales, Condiciones de Trabajo. 


\section{Introdução}

As ações do Estado traduzem poucas iniciativas reais frente à realidade do campo, e não atendem ao conjunto das necessidades que este espaço apresenta. Nesse contexto, o Estado deixa nas mãos de professores, muitas vezes com pouca formação, baixos salários e sem planos de carreira o sucesso pela qualidade pedagógica nessas escolas. Dessa forma, figuram esses professores como os únicos responsáveis pelo sucesso educacional.

Para além dessas concepções, muitos movimentos sociais e sindicais do campo, como o MST, movimento de mulheres e outras organizações, recolocaram o problema da educação escolar e reivindicaram uma educação pautada na qualidade social para todos, sem a antiga oposição campo-cidade. O resultado desses movimentos se materializou nas Conferências Nacionais Por uma Educação Básica do Campo ${ }^{1}$ Considera-se importante destacar a expressão "do campo", utilizada pelos movimentos sociais nos últimos anos, para se referir à dimensão política da mobilização em favor do direito à educação básica (Weschenfelder, 2003).

A expressão "do campo" revela, portanto uma concepção e intenção política nela colocada, fazendo referência ao conteúdo de campesinato, ao sujeito social camponês, sua situação de classe e suas lutas sociais (Medaets, 2011).

A educação do campo contrapõe-se, portanto, à educação rural, no sentido que representa o esforço na direção de uma educação própria. Se de um lado o movimento da Educação do campo trouxe à luz a contribuição de um amplo arcabouço teórico, do outro recolocou a educação na agenda de negociações do Estado, e ainda mobilizou em nível nacional, a sociedade para as questões do ensino no campo, a fim de refletir sobre a qualidade dessa educação solicitada pelo movimento.

Isso implicou um envolvimento mais direto com o Estado na disputa pela formulação de políticas públicas específicas para o campo, necessárias para compensar a histórica discriminação e exclusão dessa população do acesso às políticas de Educação. (Caldart, 2010, p. 118).

$\mathrm{Na}$ contramão das legislações vigentes e solicitação dos movimentos sociais por melhores condições de ensino nas próprias comunidades, estão as turmas multisseriadas, com pouco investimento e atuação de professores desvalorizados. A quantidade de turmas multisseriadas na região do Alto Solimões é uma realidade frequente. Estas turmas possuem peculiaridades, tais como: funcionam em um mesmo espaço e ao mesmo tempo; oferecem diferentes séries e/ou etapas de 
ensino; e, são ministradas por um único professor. Em face a isto, é possível observar que a turma multisseriada possui uma organização de ensino e aprendizagem distinta da qual estamos acostumados.

Apesar da garantia de seu funcionamento na Lei de Diretrizes e Bases e Educação Nacional (LDBEN, Lei n. 9.394/96, no artigo 23), há um predomínio da visão negativa quanto à garantia do sucesso de turmas multisseriadas. Corroborando neste sentido, é comum professores, pais e alunos que não concordam com a formação das turmas multisseriadas e, tratam esta organização como sinônimo de fracasso escolar.

Segundo Hage e Rocha (2010, apud Druzian \& Meurer, 2013) os professores demonstram uma certa angústia ao trabalhar com o multisseriado. Arroyo (2006) contribui afirmando que é necessário superar a reação tão frequente contra as escolas multisseriadas, sendo necessário proporcionar aos educandos; com múltiplas idades, temporalidades, processos cognitivos e culturais, diferentes identidades; oportunidades formacionais que contemplassem a interação e novas possibilidades de aprendizado.

Este artigo pretende trazer uma discussão acerca do funcionamento de turmas multisseriadas no município de
Benjamin Constant, pertencente à região do Alto Solimões, bem como as condições de trabalho dos professores que atuam na localidade. Objetiva ainda, este estudo, abordar a concepção dos sujeitos da pesquisa acerca da escola desejada, demonstrando que parece estar bem distante do que preconiza a legislação vigente.

No decorrer deste artigo verificaremos que os números de turmas multisseriadas são bastante expressivos na região do Alto Solimões, estado do Amazonas. É possível, em vista disso, considerá-las como verdadeiras escolas no meio da floresta, quer sejam localizadas em terra firme ou na várzea, possuem especificidades que devem ser consideradas. São escolas que apesar de suas condições de funcionamento representam para a população do campo a única oportunidade de acesso à escolarização. Portanto, Retirá-las do anonimato e considerá-las como fenômenos de pesquisas é oferecer lupas para outras pesquisas e novas políticas públicas a serem implantadas na região.

\section{Marco teórico e metodológico}

A pesquisa foi desenvolvida no contexto do doutorado no Programa de Pós-graduação em Sociedade e Cultura na Amazônia da Universidade Federal do 
Amazonas - PPGSCA/UFAM e, concentrou-se em escolas rurais da região que oferecem turmas multisseriadas. $\mathrm{O}$ foco deste estudo origina-se a partir de observações em algumas turmas multisseriadas no município de Benjamin Constant, realizadas após um levantamento de escolas rurais e o multisseriado. Com as idas e vindas nessas escolas selecionou-se alguns professores que forneceram informações, por meio de depoimentos, sobre suas condições de trabalho neste cenário.

Os estudantes também puderam contribuir com a pesquisa no sentido que a partir de seus mapas mentais puderam "pintar" a escola que sonham: em meio a tantas problemáticas e desafios, querem uma escola com qualidade social, para continuidade de vida nessas localidades. O foco da pesquisa fundamenta-se na coleta de depoimentos dos professores e estudantes do multisseriado. Os depoimentos foram coletados no município de Benjamin Constant, pertencente à região do Alto Solimões ${ }^{2}$.

No município de Benjamin Constant há um total de 62 comunidades rurais. De acordo com o levantamento na Secretaria Municipal de Educação (SEMED, 2017), são 50 escolas que funcionam ao longo das comunidades, com a presença de 70 turmas multisseriadas. As crianças, adolescentes e jovens cujas comunidades onde residem não têm escolas devem efetivar matrículas em outras comunidades, que possuem escolas polos ${ }^{3}$, ou na sede da cidade, a fim de tentar garantir o acesso à educação escolar. Assim, há muitos alunos da educação infantil, ensino fundamental e médio que se deslocam de suas comunidades para ter acesso à educação formal.

Na região do Alto Solimões, como dito anteriormente, os números de turmas multisseriadas são bastante expressivas. Em Atalaia do Norte eram 58 escolas na zona rural e 26 turmas multisseriadas (dados da SEMED, 2014); em Tonantins haviam 44 escolas na área rural, com 53 turmas multisseriadas (SEMED, 2016); no município de São Paulo de Olivença eram 69 escolas na zona rural, com 47 turmas multisseriadas (SEMED, 2016); Fonte Boa eram 48 escolas também na área rural, com 202 turmas multisseriadas (SEMED, 2016). Esses dados apontam para uma realidade significativa na região, demonstrando a relevância e a necessidade de efetivação de estudos desta natureza.

\section{Escola Multisseriada, uma realidade em comunidades amazônicas}

A inserção em comunidades rurais computou vinte anos. Primeiramente na profissão docente (1998 a 2004); na 
coordenação de programa de formação de professores do campo indígenas e não indígenas, o PROFORMAÇÃO (2004 a 2006); com a inserção no magistério superior (2006 aos dias atuais), a qual culminou na dissertação de mestrado em educação (2008 a 2010), no desenvolvimento de atividades de pesquisa e extensão do Observatório da Educação do Campo - OBECAS (2014 aos dias atuais); e na tese de doutorado (2014 a 2018).

Nos diferentes contatos com as escolas e turmas multisseriadas, percebe-se que geralmente estas apresentam infraestrutura precária, prédios extenuados, materiais didáticos escassos, faltam carteiras, especificamente aquelas padronizadas para as crianças da educação infantil. Muitas escolas são unidocentes, com poucas crianças. Os livros além de insuficientes quase sempre não retratam a realidade do campo. Nas paredes há um quadro e alguns cartazes. Para a professora há uma mesa e uma cadeira na qual dificilmente pode sentar-se. Existe ainda uma salinha onde deposita-se a merenda escolar e, que muitas vezes, é feita pelos próprios professores. $\mathrm{Na}$ parte externa, tem uma casinha que funciona como banheiro, para os alunos e professores.

$\mathrm{Na}$ sala de aula há um grupo de alunos em séries diferentes. Olhares atentos, curiosos de alunos observadores. Uma sala silenciosa, de mistura em quatro paredes. Aliás, mesmo com a multisseriação a divisão das séries é presente, parece haver paredes invisíveis que separam os alunos. Hage (2014) discute que as turmas multisseriadas por mais que tenham séries diferentes acabam sendo conduzidas e orientadas pelo paradigma da seriação, pois os professores aglomeram os alunos por séries e níveis de aprendizagem em quase todas as atividades desenvolvidas na sala de aula. A seriação acaba sendo a única forma de pensar e atuar na realidade das escolas do campo, mesmo ao se deparar com a multissérie.

Ainda para Hage (2014, p. 1175), o paradigma da seriação se faz presente na escola ou turma multisseriada por meio do modelo seriado urbano de ensino, esse modelo "impede que os professores compreendam sua turma como um único coletivo, com suas diferenças e peculiaridades próprias, pressionando-os para organizarem o trabalho pedagógico de forma fragmentada, levando a desenvolver atividades de planejamento curricular e de avaliação isolados para cada uma das séries".

Hage (2014), afirma que a multissérie foi o meio possível e viável da seriação se materializar no espaço das escolas rurais, de forma bastante precária. 
"Apesar de ser necessidade no meio rural, a multissérie ainda é uma extensão do paradigma da escola seriada urbanocêntrica, pois não possui um tratamento diferenciado". (Druzian \& Meurer, 2013, p. 133).

A heterogeneidade; constituída por diferentes etapas de ensino (Educação infantil e ensino fundamental), distintas faixas etárias entre os estudantes (nas turmas multisseriadas há geralmente alunos com 4 e 5 anos até adolescentes e jovens entre 12 a 16 anos), níveis diferenciados de aprendizagem, presença de alunos com sotaque em espanhol (já que a escola está localizada em uma área de fronteira), diferentes habilidades de grupos ribeirinhos; faz da sala de aula multisseriada um lugar de encontro de diferentes culturas, logo um espaço intercultural (Ferreira, 2010; Ferreira, 2018).

Ainda que possamos reconhecer os avanços da educação do campo, no que tange à aprovação das legislações e diretrizes vigentes principalmente no tocante ao atendimento escolar no campo, ainda estamos distantes de alcançar um patamar satisfatório em relação à educação escolar oferecida em escolas e/ou turmas multisseriadas principalmente quando se fala de muitas localidades da região amazônica. Há um leque de insatisfações que imperam nos discursos dos professores e alunos das classes multisseriadas, que vão desde a precária infraestrutura escolar até às condições de deslocamento do professor.

Ramalho (2008) afirma que a multissérie não detém o primeiro lugar nesta lista de insatisfações, a primeira é a condição de infraestrutura, dificuldades no transporte, obstáculos para lidar com comportamentos sociais e culturais diferentes. Outros índices nos permitem refletir sobre essa realidade no sentido que muito já se avançou no que tange à legislação vigente, mas que pouco mudou nesta realidade.

Os dados apresentados em assentamentos rurais e áreas indígenas do país nos permitem fazer algumas análises. Em 2013 (INEP), estavam matriculados 361.361 alunos em escolas de assentamento em todo o país. Destes alunos 165 mil estavam nos anos iniciais do ensino fundamental, porém apenas 46 mil frequentavam a educação infantil. Nessa comparação poucas crianças acessam a educação infantil, a maioria já é matriculada diretamente no ensino fundamental. Entre os indígenas esses números são preocupantes também. Dos 53.800 alunos que concluíram os anos finais do ensino fundamental em 2012, 
foram matriculados no ano seguinte pouco mais de 15.800 alunos.

São nessas escolas que os índices de precariedade têm persistido. Nos dados do INEP uma comparação com os números das escolas por região demonstra as situações de desigualdades presentes na educação escolar. Sabemos que as distâncias entre as regiões norte e sul não são apenas geográficas, são principalmente educacionais. No norte há 19.568 escolas, no sul 13.959. Dessas escolas da região norte apenas $24,5 \%$ tem acesso à biblioteca ou sala de leitura; já no sul, são 76,3\%. Quanto ao acesso à internet é muito mais complexo, no norte apenas $22,1 \%$ conseguem acessar a internet, e no sul são $82,2 \%$. O acesso às quadras de esportes também é preocupante. Na região norte apenas $14 \%$ das escolas possuem quadras, no sul são $66,1 \%$.

Esses números demonstram os níveis de desigualdades educacionais por localidade, se compararmos esses números levando em consideração os dados da zona rural e turmas multisseriadas será bem mais discrepante, pois são em escolas multisseriadas que, na maioria das vezes, não é possível o acesso à biblioteca, a materiais didáticos, quase não se percebe quadra de esportes e laboratórios.

Nessa direção, Hage (2014) analisa que por mais que o acesso à etapa obrigatória (Ensino Fundamental) seja de 91,96\%, grande parte desse universo está matriculada nos anos iniciais do ensino fundamental, “em escolas multisseriadas, unidocentes, que enfrentam problemas muito sérios relacionados às precárias condições de infraestrutura e funcionamento e quanto a aprendizagem dos alunos". (p. 1.171).

Na região do Alto Solimões o retrato das escolas rurais não é um dos melhores. Há muitas discrepâncias. Assim como existem municípios com escolas bem estruturadas e conservadas na zona rural, também há escolas que nunca passaram por uma reforma, não têm acesso à água potável, tão pouco, banheiros.

No geral, as escolas multisseriadas são as que, diante dos dados apresentados, demonstram o abandono pelo poder público. Na região amazônica e mais especificamente no local da pesquisa, essa realidade é perceptível quando se observa a infraestrutura. Muitas vezes, no primeiro momento, nem parecem escolas. Sem placa de identificação. Mais parecendo um barracão, o que demonstra um verdadeiro descaso. Contudo, essa situação não é unânime. Há escolas multisseriadas muito organizadas na área rural; há escolas recém-inauguradas, em alvenaria, com mobílias novas, banheiros e acesso à água potável. 
Além do número de turmas multisseriadas no município de Benjamin Constant encontra-se ainda as turmas multietapas, que são as turmas organizadas da educação infantil ao $5^{\circ}$ ano do ensino fundamental. Por mais que a legislação educacional não permita a junção de duas etapas de ensino diferentes na mesma turma, é comum estas serem formadas pelo Pré I e II e anos iniciais: "Em nenhuma hipótese serão agrupadas em uma mesma turma crianças de educação infantil com crianças do ensino fundamental" (Resolução n. 02/ 2008, Art. 3 $3^{\text {o }} \S 2^{\circ}$ Diretrizes Complementares da Educação do Campo).

Todavia, o problema mais grave reside na formação de turmas compostas por alunos que vão desde o Pré I ao $5^{\circ}$ ano. No total há 22 formadas com duas etapas (multietapas); são 22 professores que atuam nessas condições, contrariando a legislação. As turmas variam de 9 a 27 crianças, totalizando 364 crianças que são submetidas cotidianamente à condição de desvantagem material e de atenção do professor. São turmas em que os aspectos relacionados ao educar e cuidar de crianças da educação infantil de 4 e 5 anos são violados.

Diante de tal realidade, parece não haver um parâmetro que oriente a formação das turmas multisseriadas e multietapas. E, em face disso, surgem questionamentos, tais como: Por que é permitido formar uma turma com 9 alunos e a outra com 27? Quais os critérios utilizados para essa divisão?

Como possíveis respostas, supõe-se que em se tratando da turma de 27 alunos, talvez seja por conta do número insuficiente de salas de aula disponíveis. Urge a necessidade imediata da construção ou ampliação de escolas. Há outras implicações também que envolve a contratação de mais professores, alterando os gastos dos recursos disponíveis. Enfim, as justificativas variam, suscitando mais pesquisas sobre essa temática.

De acordo com a lei aprovada no Conselho Municipal de Educação (CME, 2015) a formação de turmas no ensino fundamental será até de 25 alunos, incluindo as matrículas de duas crianças com necessidades educacionais especiais. Nas turmas de educação infantil Pré I e II, já incluindo duas crianças com necessidades educacionais especiais, podem ter até 20 alunos. A lei não trata das turmas multisseriadas, sendo de extrema necessidade a discussão deste item. Percebe-se que o poder público tem nas mãos o controle das decisões e a consulta à comunidade continua sendo vedada.

Em meio a desafios e contrariedades, a voz dos professores enfatiza as 
dificuldades existentes em desenvolver suas aulas neste cenário. Durante a pesquisa foram coletados depoimentos de 19 professores, que serão trazidos em todo o artigo, a fim de entender suas condições de trabalho em turmas multisseriadas. Analisando alguns relatos foi possível entender que não existem receitas prontas para desenvolver o trabalho pedagógico, sobretudo em turmas multisseriadas. Ficou evidente que para além das problemáticas vivenciadas os professores acumulam saberes da experiência que impulsionam suas práticas nestes contextos. Exemplo disso é abordado no documentário francês Ser e ter (2002), que trata a prática pedagógica de um professor em uma turma multisseriada e as diferentes possibilidades que vai sendo construída cotidianamente.

Por outro lado, alguns relatos coletados dão conta da complexidade do ensino multisseriado:

A maior dificuldade que encontrei na sala multisseriada é que os alunos que já são bem avançados e têm alunos que não acompanham $\mathrm{o}$ professor isso dificulta muito $\mathrm{o}$ trabalho. No caso a educação infantil está junto aos anos iniciais (C. P., 29 anos, entrevista com Professor, 2017).

A visão que eu tenho é que nenhum professor gostaria de trabalhar com turmas multisseriadas, porque a dificuldade é maior do que as demais turmas ..., por mim se fosse para erradicar seria melhor (E. N., 38 anos, entrevista com professor, 2017).

No meu caso a sala de aula é muito pequena, falta espaço, além disso, a mesma sala de aula serve de cozinha para servir merenda (J. N., 33 anos, entrevista com professor, 2017).

Vale ressaltar que o problema parece não ser pelo tipo de organização multissérie, pois sua qualidade não pode ser inferior à nenhuma escola, inclusive das escolas da cidade. O fato é que ainda persiste a implantação de modelos de currículos urbanos dentro do rural e, sobretudo com atuação de professores sem formação específica para atuação neste contexto escolar, gerando verdadeira atribuição unicamente ao multisseriado como responsável pelo insucesso escolar.

\section{As turmas multisseriadas e as condições de trabalho}

A legislação educacional brasileira (LDBEN n. 9394/1996) traz um item dedicado às condições de trabalho docente. $\mathrm{Na}$ trajetória das legislações educacionais este texto traz um avanço no item da valorização dos professores, ao citar diversas dimensões a serem consideradas neste âmbito, preconizando no artigo 67 do referido instrumento que:

Os sistemas de ensino promoverão a valorização desses profissionais da educação, assegurando-lhes, inclusive nos termos dos estatutos e 
dos planos de carreira do magistério público:

I- Ingresso exclusivamente por concurso público por provas e títulos; II- Aperfeiçoamento profissional continuado, inclusive com licenciamento periódico remunerado para este fim;

III- Piso salarial profissional;

IV- Progressão funcional baseada na titulação ou habilitação, e na avaliação do desempenho;

V- Período reservado a estudos, planejamento e avaliação, incluído na carga de trabalho;

VI- Condições adequadas de trabalho.

Dentre os princípios da valorização docente são garantidos as condições adequadas de trabalho, mas o que é observado na escola rural multisseriada é a negação desse direito, causando um verdadeiro mal-estar docente, evidenciado em seus baixos salários, desqualificação, estigmas e desvalorização profissional.

As condições de trabalho docente, seus baixos salários chamam atenção nos noticiários e a mídia assume um espaço privilegiado para a propagação do estigma de não optar por ser professor no país. Em cursos de licenciaturas é comum ouvir falas de acadêmicos que dizem não querer "dar" aulas, refletindo a desqualificação em ser professor. No Brasil, ser professor, pelo histórico processo de desvalorização, não é uma profissão muito almejada, "sendo alvo de críticas e piadinhas devido ao baixo status social". (Rodrigues, 2009, p. 140).
Por tudo que já foi verificado sobre as condições de trabalho do professor da escola multisseriada, no contexto observado, é possível concluir que os princípios da valorização presentes na legislação são pouco considerados na realidade dessas escolas.

Existe um conjunto de elementos legais que estabelecem a garantia da valorização docente. Dessa forma, não basta apenas ter formação em nível superior, há que considerar bons salários, formação profissional e condições de trabalho favoráveis. No caso particular do professor da sala multisseriada da região, tratar sobre condições de trabalho é um aspecto mais complexo, pois além desses princípios constitucionais ainda existem questões relacionadas ao transporte, à moradia e às diferentes funções na tarefa de ensinar.

Nessas escolas multisseriadas o desafio é maior. Em muitas destas, os professores são os únicos funcionários, não tendo apoio de nenhum profissional para o acompanhamento e orientação do trabalho pedagógico. Não tem merendeiro, nem serviços gerais, Eles figuram como responsáveis para desempenhar as diferentes funções. Vale ressaltar, que geralmente esses professores são iniciantes no magistério. 
Além disto, nessas escolas, ter laboratórios de ciências, quadra de esporte, refeitórios, transporte adequado para professores e alunos, é "sonhar muito alto". Soma-se ainda como problemática, a falta de água potável e merenda escolar. Muitas vezes, nem banheiro existe. Um cenário que marca a existência de muitas escolas multisseriadas que encontramos nas comunidades rurais da região.

Trindade e Werle (2012) esclarecem que as questões que vão desde o deslocamento, o transporte, moradia na comunidade, salários, até a multiplicidade de suas funções para atender o dia-a-dia escolar estão ligadas às dimensões objetivas de suas condições de trabalho.

Neste contexto, os professores são considerados "guerreiros", "heróis", por deixarem sua família na cidade, por percorrerem horas em um transporte inadequado até à comunidade. Também são considerados assim por serem capazes de trabalhar com todas as séries em uma mesma turma com poucas condições, desempenhando ainda as outras funções para além do trabalho docente. Estes profissionais lidam com os estereótipos de serem professores rurais, muitos com pouca formação, às vezes, até mesmo somente o magistério, sem acesso à internet, ou outras fontes de informação. Quanto pior, quando falta energia elétrica

e, todos acabam sendo isolados nessas comunidades, onde a leitura é quase inexistente.

Esses professores sofrem com a contratação temporária, por representarem peso político para grupos que têm o poder de manobrar as lotações na área rural, tornando a comunidade e a escola como "currais eleitorais". Além disso, são vítimas de um sistema de interesses políticos entre grupos que quase eternizam o poder em municípios da região. Então, muitos destes, chegam às comunidades sem muitos prestígios, aproveitando a chance de trabalharem como contratados, por fazerem parte do grupo político que naquele momento está no poder.

Assim, é notório afirmar que para se falar em qualidade na educação em qualquer contexto, é necessário considerar as condições de trabalho com que os profissionais são submetidos no espaço de atuação. Hypólito (2012) contribui dizendo que não se pode falar de qualidade de ensino se as condições de produção de trabalho de ensinar persistem precárias. Oliveira e Vieira dizem que:

A divisão das tarefas e
responsabilidades, a jornada de
trabalho, os recursos materiais
disponíveis para o desempenho das
atividades, os tempos e espaços para
a realização de trabalho, até as
formas de avaliação de desempenho,
horários de trabalho, procedimentos
didáticos-pedagógicos, admissão e


administração das carreiras docentes, condições de remuneração. (Oliveira \& Vieira, 2012, p. 157).

Na mesma direção Contreras (2012) pondera que o trabalho docente sofreu tamanha subtração progressiva de qualidades a ponto de tornam esses professores vítimas de um sistema organizacional em que eles perderam o controle e o sentido do próprio trabalho.

Dessa forma, a questão das condições de trabalho envolve o tipo de contratação que este professor adquire. $\mathrm{O}$ tipo de vínculo com o sistema de ensino vai dizer muito quanto à sua valorização profissional. Na história da educação do país os processos de desvalorização docente perpassaram muito pelo entendimento do seu tipo de vínculo, tornando o trabalho docente na área rural um mecanismo de controle por parte de políticos ou fazendeiros, que aliciavam e dominavam a lotação nessas localidades. Mantendo formas de controle e número de votos a partir das manobras entre a comunidade e o ensino. Nesse viés o cargo de professores era tido como moeda de troca. Dessa maneira, era quase impossível se falar em valorização docente pela dimensão contratual de trabalho. Após a aprovação na legislação atual referente ao vínculo mediante concurso público houve alterações na forma de pensar a valorização docente.

Mesmo com a legislação vigente tem-se desenvolvido formas de contratação temporária de professores na área rural, desqualificando o trabalho docente nestes espaços. Em levantamento realizado em cinco municípios do Alto Solimões obtevese o número de professores que atuam em regime de contratação temporária na área rural. $\mathrm{Na}$ área rural, geralmente são lotados professores com menor titulação e aqueles contratados de forma temporária.

Esses dados são referentes aos números de professores que atuam na área rural, conforme levantamento realizado nas secretarias de educação municipais (2016) e nos registros do Observatório da Educação do Campo no Alto Solimões (OBECAS, 2014). Nos municípios de Benjamin Constant e Atalaia do Norte os dados foram coletados em 2014, não sendo possível ainda a atualização. Já em São Paulo de Olivença, Tonantins e Fonte Boa os dados foram coletados em 2016.

Em Benjamin Constant dos 294 professores, 203 trabalhavam em regime temporário e 91 eram efetivos mediante concurso público. No município de Atalaia do Norte foi informado apenas a situação dos professores não indígenas. Dos 37 professores não indígenas 24 trabalhavam em situação de regime de contratação e 13 
efetivos. No município de São Paulo de Olivença eram 487 professores. Desse universo, 112 eram contratados temporariamente e 375 efetivos. Em Tonantins dos 151 professores, 88 atuavam em regime de contratação e 63 eram efetivos. Em Fonte Boa não foi informado quanto à situação de vínculo, apenas informaram que no município atuavam 182 professores na área rural.

Os números nos dizem muito da situação da valorização e das condições de trabalho da escola do campo, bem como do multisseriado. Verifica-se que apenas um município citado possui o número de professores efetivos superior aos contratados, os outros todos têm preponderância na contratação temporária, apesar da legislação estabelecer o contrário. Um dos problemas em decorrência do tipo de vínculo é a alta rotatividade apontada pelos professores. Em entrevista, os professores apontaram este problema. Sem ter muito o que fazer ou reclamar, acabam aceitando e se submetendo a situação visto à necessidade de emprego. Hage (2006) considera que:

Nessas escolas, o trabalho docente, tem pouca autonomia em face das questões políticas que envolvem o poder local e interferem nas dinâmicas das secretarias de educação, submetendo os professores a uma grande rotatividade (mudança constante de escola), em função da sua instabilidade de emprego. (p. 308).

Devido a tantos entraves e complexidades do trabalho docente na área rural são comuns os constantes pedidos de transferência para a zona urbana, contribuindo também para o aumentando da rotatividade. Assim, a escola rural fica como um teste para muitos professores iniciantes, que tudo fazem para que a lotação na cidade ocorra. Por outro lado a análise necessita ir para outros prismas, primeiramente, conforme todos os desafios apontados na escola do campo, poucos profissionais se sentem motivados a trabalhar nesses locais. Depois, sem muito ou nenhum investimento em políticas de fixação de professores na zona rural é muito difícil atrair profissionais para essas escolas.

Neste cenário, o salário do professor diz muito de sua satisfação em ser professor do campo. As pesquisas demonstram que os professores do campo historicamente e, ainda atualmente, possuem os menores salários, isso em detrimento de sua menor titulação. Pois ainda é bastante comum o número significativo de professores leigos atuando principalmente em turmas multisseriadas. Quanto menor a titulação, menor seus vencimentos. Em questionário aplicado aos professores sujeitos da pesquisa, todos 
afirmaram que estão insatisfeitos com seus salários. Assim, os professores se submetem a um sistema em que se desdobram em mais de uma escola para atender às suas condições razoáveis de sustento. Os professores da zona rural geralmente possuem um segundo turno na zona urbana. Assim, enfrentam horas de trabalho superior a outros professores. Saem ainda de madrugada de suas casas e chegam na escola rural de manhã para enfrentar o primeiro turno. Depois se deslocam para a cidade. Almoçam rapidamente e se arrumam para enfrentar o segundo turno de trabalho.

Apesar de constar na legislação o tempo de trabalho do professor, ainda na educação básica não se concretizou a dedicação exclusiva. A partir dessa premissa poderia se ter bons salários em uma única escola com tempo dedicado ao planejamento, correção de trabalhos, bem como a inserção em processos de formação continuada dentro da carga horária. Nessas condições o professor não teria que enfrentar duplas jornadas de trabalho, em diferentes escolas, muitas vezes em escolas da área rural e urbana, sem tempo para a família e para o lazer, implicando na sua qualidade de vida.

Nesse contexto é necessário considerar os aspectos subjetivos do trabalho do professor. Hypólito (2012) pondera o tempo de preparo para as atividades de ensino, pressão emocional, valorização prestígio profissional, como elementos chave para o sucesso e a qualidade do trabalho desse profissional.

No entanto ser professor rural perpassa por muitos adjetivos que não são animadores quando se pensa ou se é professor do beiradão ${ }^{4}$. Além de serem desvalorizados em relação aos seus vencimentos, o seu constante ir e vir em canoas que muitas vezes são superlotadas e sem segurança, atuando em escolas precárias, carregam muitos estigmas, pois ninguém consegue se orgulhar de uma profissão com tamanhos desafios. Hernandez (1998) diz que as condições materiais das escolas e os salários dos professores são alicerces para o reconhecimento social do trabalho docente.

De acordo com dados do INEP (2011), dos 160.317 professores que atuam no campo, quase metade não possui ensino superior $(46,7 \%)$ e ainda $97,4 \%$ atuam apenas com ensino médio e 2,6\% atuam com ensino fundamental (Hage, 2014). Esses números demonstram os desafios quanto à formação docente em um período em que pese às exigências por nível superior e ainda se pensarmos na meta 15 do Plano Nacional de Educação atual (2014- 2024) que estabelece formação em nível superior na área em que atuam e, 
ainda, a meta 16 que estipula um prazo até 2024 para a formação em pós-graduação dos $50 \%$ de docentes que atuam no país.

Os mapas mentais e argumentos dos professores, alunos e comunitários sobre a escola que eles querem nos indicam algumas pistas para pensar as contrariedades da escola no campo, apontando para outros olhares que permitem incidir sobre políticas públicas que tardam a chegar à região.

\section{A escola do campo que queremos}

Durante a coleta de dados em turmas multisseriadas realizou-se oficinas de desenho com as crianças na qual elas, por meio de seus mapas mentais, mostraram a escola que elas gostariam de ter. As oficinas foram realizadas nas próprias comunidades, nas dependências da casa de reunião e na escola.

Figura 1: O caminho da escola (Darlei, 12 anos).

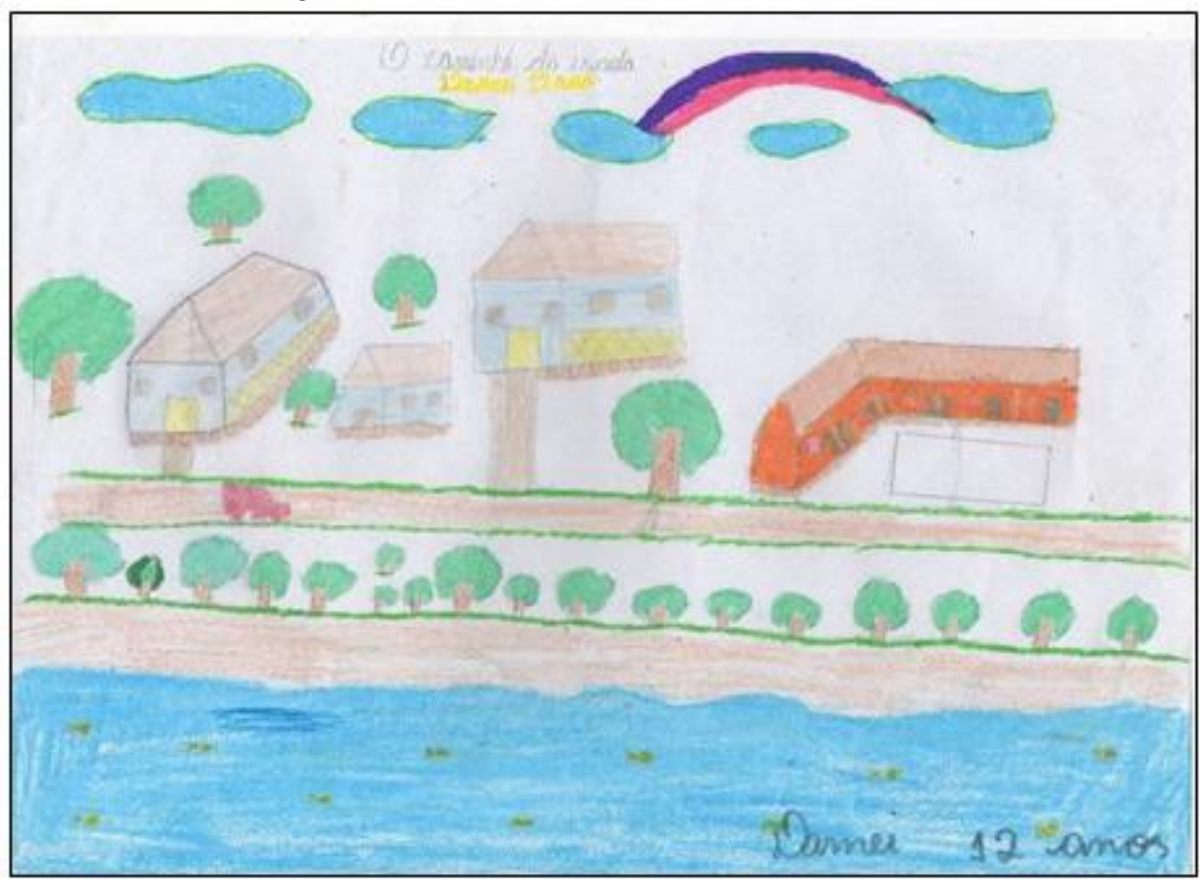

Fonte: Pesquisa de campo. Ferreira (2016).

São comuns os desenhos das crianças expressarem o que elas não conseguem ter no dia-a-dia da escola. Então, muitos dos desenhos apresentam principalmente $\mathrm{o}$ apelo pela estrutura e infraestrutura escolar, como escola de alvenaria, com quadra, até piscina é solicitada. Estes desenhos transitam pelo caminho das políticas públicas pouco implementadas na escola do campo. Demonstram a contrariedade da implementação do Programa Luz para todos que possibilitou a instalação da energia elétrica nas comunidades, rurais, porém indisponível 
em muitas escolas. Evidencia a falta de banheiro adequado, até falta de água potável. Eles solicitam por merenda escolar todos os dias.

Alguns desenhos dentre muitos chamaram atenção, umas crianças colocaram que gostariam de helicóptero, e outra que queria pelo menos um cavalo, um carro. Em conversa com as crianças percebeu-se a necessidade que estas têm de transporte escolar. Um grupo de cinco irmãos alunos da escola São José, moram em uma comunidade vizinha (São Raimundo), e todos os dias percorrem uma hora para ir e uma hora para retornar às suas casas. $\mathrm{Na}$ comunidade que elas moram não tem escola e "elas vão e vêm brincando professora todos os dias, e é dificil elas faltarem aula” (M. S., 30 anos, 2016).

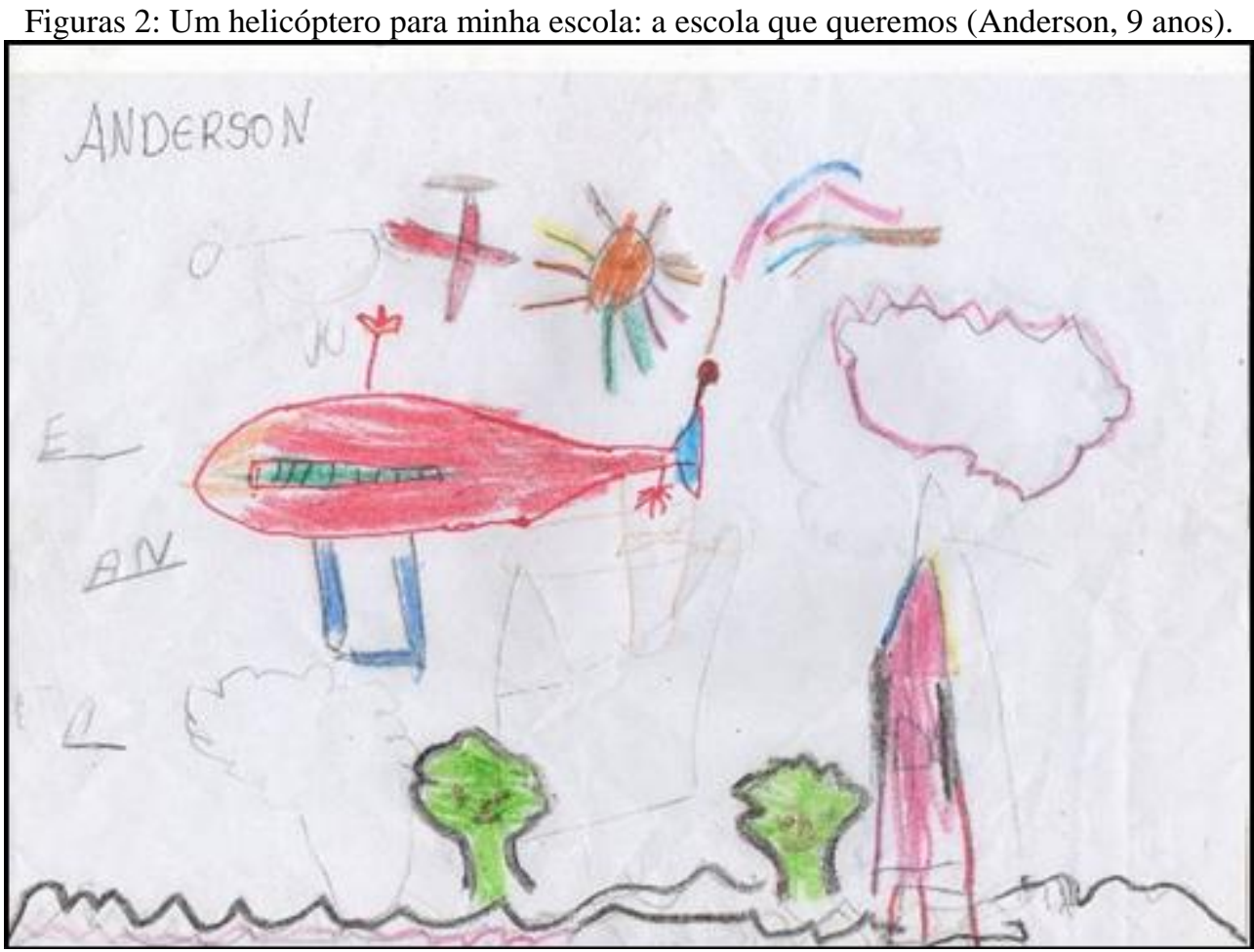

Fonte: Pesquisa de campo. Ferreira (2016)

Por outro lado, outras crianças expuseram suas vontades em escolas pintadas com muitas flores, jardim e muita cor. Desejando uma escola mais próxima da natureza, com mais verde. Isso demonstra que não é pelo fato de estudar em uma escola no meio da floresta que a faz preocupada com as questões ambientais. Esses desenhos dizem muito quando pensamos que estas escolas precisam implementar nova temáticas. Pois, estas escolas podem estar continuando um trabalho "de costas" para o contexto local e para os anseios e 
intencionalidades da comunidade. Ou seja, a escola continua a ser um espaço estranho e com características urbanas, no momento em que não considera o ambiente ao seu redor.

Figura 3: A escola e minha comunidade (Lucas, 9 anos).

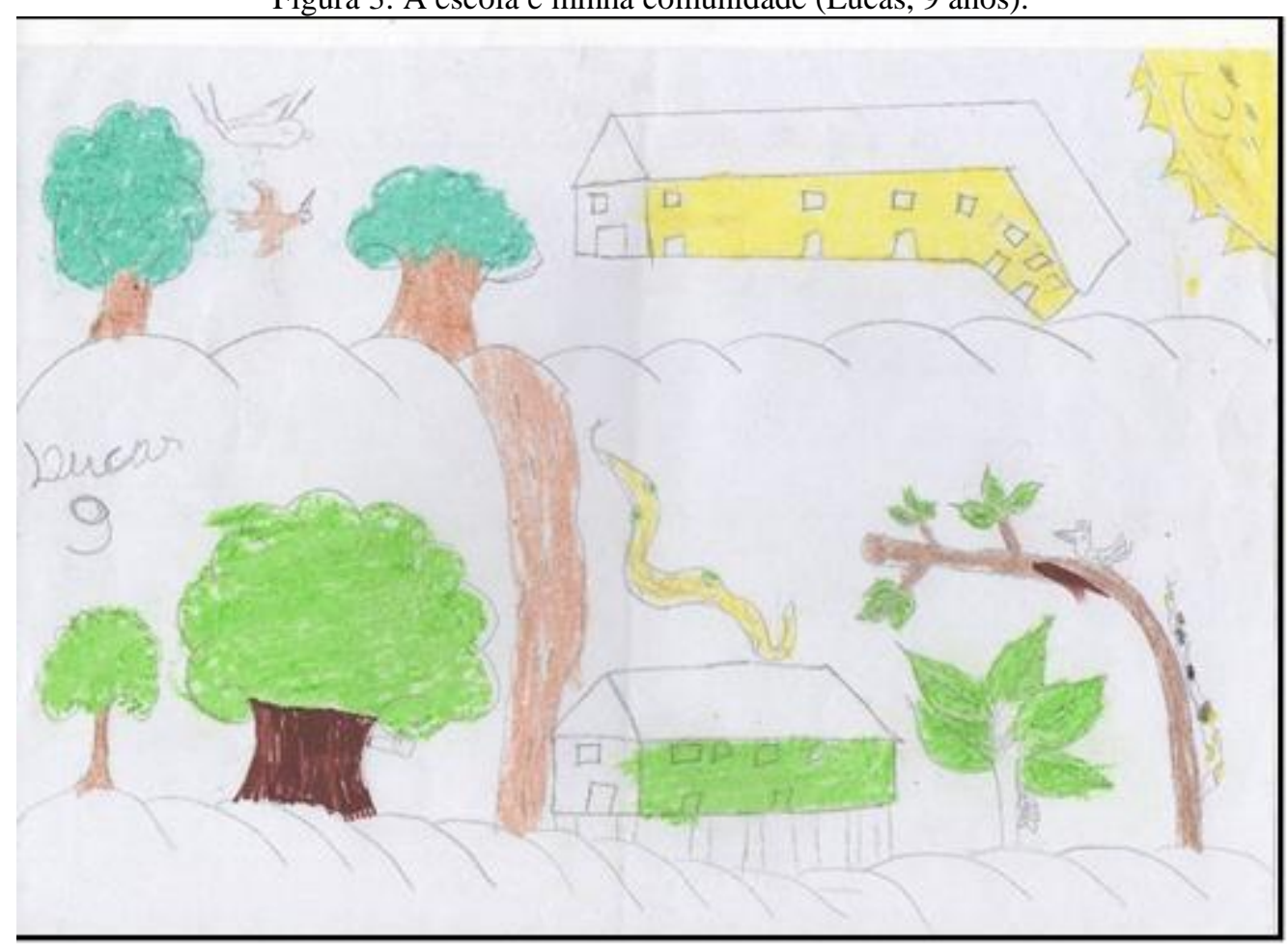

Fonte: Pesquisa de campo. Ferreira (2016).

Outros desenhos apelam para a paisagem ligada também com a identidade da floresta. Nestes, as crianças solicitam jardim, árvores, querem o verde próximo à escola, pois é comum derrubarem muitas árvores para as construções. Outro desenho chamou atenção, uma criança da educação infantil colocou em seu desenho uma casa na árvore, pois gostaria de brincar todos os dias na escola. Percebe-se assim o apelo ao brincar, pois estas crianças, geralmente, se sentem presas em escolas com poucas condições de funcionamento, sem muitos atrativos, quentes, superlotadas e sem materiais didáticos.

A visão dos professores $\mathrm{e}$ comunitários em relação à escola que eles querem, também se assenta na ideia daquilo que, frequentemente, estes não conseguem usufruir nas escolas do campo.

Os professores se queixam principalmente do deslocamento. Eles dizem ter que acordar muito cedo para pegar o barco que sai sempre antes das 6 
da manhã. Eles enfrentam um barco pequepeque $^{5}$ superlotado, inadequado e sem segurança. Muitos não usam colete salvavidas em sua viagem diária. Também se queixam da escola onde atuam, por não oferecer condições mínimas de higiene, muitas escolas sem água potável.

Acordo às 5:00 da manhã, saímos do porto às 5:50. Chegamos na escola às 6:45; a caminhada até a escola varia, quando o rio está cheio, gastamos mais 5 minutos, quando o rio está seco uns 20 minutos, pode ser mais ou menos. Saímos da escola umas 11:35 e chegamos na cidade por volta de meio dia e quinze (I. A. T., 26 anos, entrevista com professora, 2017).

Os professores e os comunitários concentraram-se igualmente, tal como as crianças nas questões relacionadas à estrutura e infraestrutura escolar. Querem uma escola em alvenaria, climatizada, com secretaria, biblioteca, sala de informática e banheiros. Essa escola muito pautada no modelo da escola da cidade, referente à sua estrutura em alvenaria e climatizada.

Percebe-se que uma escola sendo na área rural também poderia oferecer conforto para os professores e crianças que ali estão. Porém há muitos equívocos referentes à construção da escola do campo na região. Comumente, as escolas que estão sendo construídas ultimamente são em alvenaria, valorizando uma padronização das escolas da cidade, assim sendo, consequentemente precisariam, principalmente, de climatização, ou seja, com isso, haveria a necessidade de investimento na energia elétrica e manutenção dos equipamentos.

Mas na prática não é o que ocorre, pois muitas escolas recém-construídas não dispõem de ares condicionados em suas salas de aula, ou esses equipamentos acabam apresentando problemas muito cedo. Nesse contexto, acaba-se criando outros problemas para a escola do campo, pois se houvesse a construção de escolas com identificação com o clima de seu contexto, outros modelos poderiam ser implementados.

Outro sonho esboçado pautou-se no item "valorização e formação de professores". Para eles (professores), uma escola seria "muito boa" se todos fossem formados na disciplina de sua atuação. Pois é muito comum professores com desvio de função. Às vezes, são licenciados em matemática e completam sua carga horária com física, química, etc. Os professores, neste aspecto, ainda solicitam outros cursos de formação continuada para a constante qualificação.

Acredito que ser educador do campo, já é o maior desafio, desafios esses que iniciam desde o momento em que acordo até a volta para a casa, uma luta árdua e diária que também perpassa pelo desenvolvimento de um ensino multisseriado até questões internas e externas que influenciam 
no rendimento escolar dos alunos e a própria desvalorização profissional e salarial (I. A. T., 26 anos, entrevista com professor, 2017).

Gostaria que tivesse mais apoio da SEMED com materiais didáticos e outras vezes formação continuada ( $R$. C., 33 anos, entrevista com professor, 2017).

Acredito que a luta não seja só minha, a escola se encontra em condições humanas precárias. A infraestrutura inadequada, na sala onde trabalho é cozinha ao mesmo tempo é uma espécie de biblioteca. $\mathrm{O}$ espaço é pequeno que compromete o desenvolvimento das atividades. $\mathrm{O}$ ideal seria a escola possuir suas dependências específicas (I. A. T., 26 anos, entrevista com professor, 2017).

Estes relatos demonstram que muitos professores do multisseriado, apesar de todas as precariedades, continuam firmes e resilientes, dando seu melhor a cada etapa, reconstruindo seu fazer pedagógico a cada experiência e desafio enfrentado. Souza (2011) diz que as vozes e as experiências formativas desses sujeitos do espaço rural devem ser consideradas nos estudos das diversas ruralidades.

Outro item apontado referiu-se as novas tecnologias na escola, tais como: acesso à internet, sala de informática, sala de mídias, laboratório de ciências. Como sabemos o Brasil sofre com a infraestrutura tecnológica. Lugares muito distantes dos grandes centros, especialmente na região Norte há pouca cobertura de sinal de internet, principalmente em muitas comunidades rurais amazônicas isso tem sido um desafio. Por exemplo, nas escolas em que realizamos a pesquisa nenhuma tinha acesso à internet, nem computadores e, muitas com energia elétrica apenas na secretaria.

Uma sala de emergência também foi apontado pelos professores. Isso porque, como é comum não ter nem um posto de saúde nas comunidades, então os próprios professores temem situações emergenciais, como acidentes que venham a sofrer em localidades de difícil acesso.

Os comunitários argumentam mais com base na participação e proposta de ensino da escola. Para eles da forma como eles vivenciam o trabalho na comunidade, a escola também deveria seguir esse rumo:

Eu sempre mostro pra ela (se referindo a sua filha), você sozinha não vai realizar, mas se tu se ajuntar com tuas outras irmãs esse sonho será realizado, não só com as irmãs, mas com teus pais, teus avós, com os comunitários e se chegar a conversar com os primos, com a sociedade, esse sonho será realizado. Então eu acho que nós pais aqui nós todos não queremos só com os professores, nós queremos professor e comunitário, tudo junto é isso que nós queremos. Se tiver algum projeto na escola a comunidade puder participar, a comunidade vai tá junto, que isso que eu acho que os pais da comunidade sonham com isso, sempre nós vinha trazendo essa tradição já de muito tempo, não é de agora não, nós temos professor já antigão, já tão velhinhos, então essa tradição a comunidade já 
vinha trazendo, junto com os professores, no caso o dia $7 \mathrm{de}$ setembro, era a escola com os comunitários, então é isso aí que os pais querem (K. U., 39 anos, entrevista com comunitário, 2016).

Por último os professores falam de um tipo diferenciado de organização do currículo, apontando a proposta pedagógica baseada na pedagogia da alternância, com tempo escola e tempo comunidade. Nota-se, diante disso, a preocupação dos professores com o tipo de vínculo que a escola deve ter com a comunidade. E, analisando a preocupação dos comunitários, acredita-se ser viável esse tipo de ensino pautado em novas formas de gestão democrática e participativa e outras formas de aprender e ensinar.

\section{Considerações finais}

O contexto do multisseriado nos obriga a pensar sobre a qualidade dos processos de ensino-aprendizagem. $\mathrm{O}$ quadro atual demanda o apontamento de novas possibilidades, outras formas de intervenção. Pois, o multisseriado quando tratado na literatura, expressivas são as colocações que levam a pensar em sua superação e menos como possibilidades. Hage (2014) diz que, sobretudo essas propostas, necessitam ser viáveis, contextualizadas e que atendam às exigências e interesses das classes a que serve, ao poder público, aos movimentos sociais

Como vimos a seriação é a forma de organização escolar muito reivindicada como solução dos graves problemas que estão presentes na escola rural. Mas, por outro lado, segundo Hage (2014), a seriação já se faz presente nessas escolas. De que forma? A multissérie foi a maneira possível e viável da seriação se materializar no espaço das escolas rurais, de forma bastante precarizada.

Ainda nos estudos de Hage (2014), o paradigma da seriação se faz presente na escola ou turma multisseriada por meio do modelo seriado urbano de ensino. Esse modelo "impede que os professores compreendam sua turma como um único coletivo", ao contrário, que possam perceber as respectivas diferenças e peculiaridades de cada uma destas, pressionando-os para organizarem o trabalho pedagógico de forma fragmentada, sobretudo incitando-os "a desenvolver atividades de planejamento curricular e de avaliação isolados para cada uma das séries". (p. 1.175).

Nesse sentido, as turmas são organizadas de modo a nos moldes da seriação, ou seja, pautada em uma concepção de ensino que fragmenta o conhecimento, aposta na padronização do 
tempo e espaço no interior das escolas, pré-defenindo o ano letivo de duração anual, com calendário único (Idem, 2014). De forma tal, a escola, com seus conteúdos fragmentados em disciplinas isoladas, se tornam o único espaço possível para o aprendizado ocorrer, nesse caminho, como vimos o conhecimento dos sujeitos do campo são negados e inviabilizados pela escola.

As aproximações que temos realizado com a realidade educacional do campo no decorrer de todo o trabalho e em outras experiências apontaram algumas pistas para referenciar propostas de intervenção nesse contexto diferenciado. $\mathrm{O}$ eixo central dessas pistas se assenta primeiramente na ideia de transgressão do modelo precarizado de seriação, pensada por Hage (2014). Em outras palavras, para a efetivação de propostas positivas nas escolas é necessário romper com o instituído, tensionar as estruturas a fim de tentar apontar outras pedagogias alternativas, rompendo com a histórica e naturalizada concepção de que na educação escolar multisseriada só há um único caminho possível.

A primeira pista que ousamos apontar se situa na participação de todos os segmentos na construção do projeto pedagógico, na proposta curricular, em seus calendários. Ou seja, quando a gestão participativa é ativada em uma escola, todos se responsabilizam pelos compromissos do sucesso escolar. Pois é comum estar presente a concepção dominante de que os camponeses não conhecem do mundo da escola, logo qualquer escola serve. Nesse pensamento, jamais se considera ou pelo menos não se cogita a ideia de participação desses sujeitos nos rumos da escola, nas tomadas de decisão.

Essa participação efetiva dos sujeitos do campo vai resultar em um amplo processo de troca de aprendizado: e, esse processo possibilitará ouvir o mundo desses sujeitos, "aprender com suas experiências de vida, de trabalho, de convivência e de educação ..., sem hierarquizar os conhecimentos, valores, ritmos de aprendizagem". (Hage, 2014, p. 1.177).

Outra pista que apontamos, assentase na velha separação entre os que pensam o ensino e entre os que estão nos campos de atuação cotidianamente, ou seja, há uma exclusão nos momentos de discussão daqueles que estão no chão da escola e da comunidade diariamente. Nesse caminho, é comum a ideia de que os especialistas, os pesquisadores, atores externos à escola, devem criar os projetos pedagógicos. Dessa forma, observa-se ainda muito latente a costumeira e antiga ideia de 
hierarquizar os saberes dos professores da educação básica e os professores de ensino superior. Fundamentando esse entendimento, Nóvoa (2009) diz que acredita-se na tendência de legitimar as "figuras de referência especialistas e universitários, sem qualquer ligação com a profissão docente". (p. 16).

Ainda de acordo com Nóvoa (2009), acrescentamos que: é necessário construir alternativas que reforcem os professores, os seus saberes e seus campos de atuação, como primeira possibilidade nesse caminho. Pois como o estudo nos mostrou há professores iniciantes, professores com mais de dez anos de atuação, significar os seus amplos processos de experiência neste contexto é desestabilizar a lógica que predomina e hierarquiza, que coloca em "seus lugares" àqueles que podem executar e àqueles que podem criar. Pois como vamos falar de multisseriado, de transgressões sem levar em consideração seus reais sujeitos.

É possível considerar outro ponto, também aliada ao pensamento de Hage (2014) e diz respeito à valorização da interculturalidade, ou seja, reconhecer a multiplicidade de culturas e identidades/ subjetividades existentes na sala de aula multisseriada. Não se pode negar a heterogeneidade presente; não se pode tratar igual o que é diferente.
No costume de tudo homogeneizar e da nossa pouca experiência com processos interculturais, nossa primeira ação é reclamar, dizer que está errado, que não consegue, que na cidade é diferente e melhor. Então, qual a solução: tornar possível a seriação, a homogeneização, mesmo em um espaço heterogêneo, pois este é a única forma que sabemos fazer? Nesse caso, faltariam somente as paredes concretizadas para separar as séries, mas simbolicamente elas já estão ali, quando se separa todas as crianças da educação infantil e primeiros anos, preferencialmente próximas à mesa da professora e, colocam de frente para o quadro, as crianças do $4^{\circ}$ e $5^{\circ}$ ano. Por outro lado sabemos que é possível utilizar a heterogeneidade como algo positivo e não como problema, demonstrando o quanto pode ser proveitoso a aprendizagem dos alunos mais velhos com os alunos mais novos.

O multisseriado interfere em nossa zona de conforto, somos desafiados e, no atual sistema de ensino, você só precisa passar da fase do desespero e se acomodarse nas regras do jogo, ou seja, seriar o que é múltiplo. Passando essa fase a próxima é naturalizar, dizer que tudo é assim mesmo, que não tem jeito, que eles são lentos. Aí se separam os "lentos", daqueles mais "adiantados"; àqueles que já conseguem 
tirar do quadro, daqueles que ainda é preciso segurar na mão para fazer o nome e, assim, vão se passando anos e anos trabalhando com o multisseriado, se tornando especialista nesse processo, mas sem tentar nenhuma forma de modificar as estruturas de poder que ali são postas, sem tão pouco tentar romper com forças e pensamentos instituídos e naturalizados que permeiam as mentes e as ações daqueles que se deparam com esse tipo de ensino.

Faz-se necessário apontar ainda um outro norte a ser considerado, que é tentar superar a visão do currículo escolar centrada nas disciplinas, entendidas como fragmentos engavetados

em compartimentos fechados, que oferecem ao aluno algumas formas de conhecimento que pouco tem a ver com os problemas reais, dos saberes fora da escola (Hernandez, 1998). Nesse aspecto, há predominância na fragmentação do saber, apartando as possibilidades de diálogo horizontal entre as áreas de conhecimento.

Essa lógica se justifica em uma visão sequencial, homogênea dos processos mentais, da aprendizagem e do desenvolvimento (Arroyo, 2009). Nessa lógica os conteúdos são na visão acumulativa e inflexível, nessa sequência, as etapas não podem ser queimadas.
Nesse sentido, vamos percebendo aos poucos que apenas o modelo seriado que tanto insistimos como o único caminho, talvez não seja o único possível. Não podemos entrar na ideia de que um modelo é melhor que o outro, pois estaríamos trazendo para a discussão algo que já foi superado, o que estamos tentando refletir são as diferentes possibilidades do multissérie e entender que precisamos tentar muito mais do que dizer da sua ineficiência antes mesmo de tentar fazer diferente.

Arroyo (2009), com base em Bruner, afirma que somos a espécie intersubjetiva por excelência, e essa é nossa condição humana e ninguém e nenhum contexto pode nos tirar. Somos uma comunidade de interação e a escola deve recuperar sua função a de ser uma instituição de coletividades e intercâmbios. A multissérie nos permite pensar em outros tempos e espaços escolares. Ou seja, em que as pessoas saiam de seus isolamentos, onde as pessoas possam se encontrar, dialogar, trocar vivências, valores, símbolos, saberes e significados. Isso tudo nos sugere outras formas de pensar a educação do campo, em desenvolvimento nas florestas e terras da Amazônia.

\section{Referências}


Arroyo, M. (2009). Ofício de mestre: imagens e auto-imagens. Petrópolis, RJ: Vozes, 9-24.

Arroyo, M. G. (2006). A escola do campo e a pesquisa do campo: metas. In: Molina, M. C. (Org.). Educação do Campo e Pesquisa: questões para reflexão (pp. 103116). Brasília: Ministério do desenvolvimento Agrário.

Batista, F. M. C. (2003). Educação Rural: das experiências à política pública. Brasília: NEAD.

Caldart, R. S. (2010). Educação do Campo: notas para uma análise de percurso. In Molina, M. C. (Org.). Educação do Campo e Pesquisa II: questões para reflexão (pp. 103-126). Brasília: MDA/MEC.

Censo Escolar da Educação Básica: Resumo técnico. (2013). In INEP Instituto Nacional de Estudos e Pesquisas Educacionais Anísio Teixeira. Brasília.

Contreras, J. (2012). A autonomia de professores. São Paulo: Cortez.

Druzian, F., \& Meurer, A. C. (2013). Educação do campo multisseriada: experiência docente. Geografia Ensino $e$ Pesquisa, 17(2), 129-146.

Ferreira, J. S. (2010). E o rio, entra na escola? Cotidiano de uma escola ribeirinha no município de Benjamin Constant/AM e os desafios da Formação de seus Professores (Dissertação de Mestrado). Universidade Federal do Amazonas, Manaus.

Ferreira, J. S. (2018). A escola na floresta: manifestações culturais e processos educativos em comunidades tradicionais do Alto Solimões (Tese de Doutorado). Universidade Federal do Amazonas, Manaus.
Hage, S. M. (2006). Educação do Campo na Amazônia: retratos de realidade de escolas nultisseriadas no Pará. Belém: Gráfica e Editora Gutenberg Ltda.

Hage, S. M. (2014). Transgressão do paradigma da (multi) seriação como referência para a construção da escola pública do campo. Educ. Soc., 35(129), 1.165-1.182.

Doi:

http://dx.doi.org/10.1590/ES0101-

$\underline{73302014144531}$

Hernandez, F. (1998). Transgressão $e$ mudança na educação: os projetos de trabalho. Porto Alegre: Artmed.

Hypolito, A. M. (2012). Trabalho docente na Educação Básica no Brasil: as condições de trabalho. In Oliveira, D. A., \& Vieira, L. F. (Orgs.). Trabalho na Educação Básica: a condição docente em sete estados brasileiros (pp. 111-129). Belo Horizonte, MG: Fino Traço.

Lei de Diretrizes e Bases de 20 de dezembro de 1996 (1996, 20 de dezembro). Estabelece a Lei de Diretrizes e Bases da Educação Nacional. Diário Oficial da União, seção 1.

Medaets, C. V. (2011). Práticas de transmissão e aprendizagem no Baixo Tapajós: contribuições de um estudo etnográfico para educação do campo na Amazônia. In Anais da 33a Reunião Anual da ANPED. Rio Grande do Norte, Natal.

Novoa, A. (2009). Professores, imagens do futuro presente. Lisboa: EDUCA.

Oliveira, D. A., \& Vieira, L. F. (2012). Condições de trabalho docente: uma análise a partir de dados de sete estados brasileiros. In Oliveira, D. A., \& Vieira, L. F. (Orgs.). Trabalho na Educação Básica: a condição docente em sete estados brasileiros (pp. 153-190). Belo Horizonte, MG: Fino Traço. 
Ramalho, M. N. M. (2008). Na roça, na raça... eu me tornei professor: um estudo sobre a formação docente de professores de classes multisseriadas no norte de Minas Gerais e Vale de Jequitinhonha (Tese de Doutorado). Universidade Metodista de Piracicaba, São Paulo.

Resolução n. 2. (2008, 28 de abril). Estabelece diretrizes complementares, normas e princípios para o desenvolvimento de políticas públicas de atendimento da educação básica do campo. Brasília, DF: Presidência da República.

Rodrigues, C. L. (2009). Educação no meio rural: um estudo sobre classes multisseriadas (Dissertação de Mestrado). Universidade Federal de Minas Gerais, Minas Gerais.

Souza, E. C., et al. (Orgs.). (2011). Sujeitos, instituições e práticas pedagógicas: tecendo as múltiplas redes da educação rural na Bahia. Revista da FAEEBA: Educação $e$ Contemporaneidade, 20(36), 151- 164. Doi:

http://dx.doi.org/10.21879/faeeba23580194.2011.v20.n36.p\%25p

Trindade, L. M., \& Werle, F. O. (2012). O ensino no meio rural: uma prática em extinção. In Souza, E. C. (Orgs.). Educação e ruralidades: memórias e narrativas (auto) biográficas (pp. 31-50). Salvador: EDUFBA.

Weschenfelder, N. V. (2003). Uma história de governamento e de verdades: a educação rural no RS 1950/1970 (Tese de Doutorado). Universidade Federal do Rio Grande do Sul, Porto Alegre.

\footnotetext{
${ }^{1}$ Essas conferências ocorreram nos anos de 1998 e em 2004, em Luziânia, resultado de uma ampla mobilização e debate nacional. A intensa mobilização recolocou na agenda do poder público a educação no espaço rural do país, trazendo para o
}

cenário nacional a possibilidade de discussão e elaboração de um novo projeto educativo nascido do próprio campo. Também foi criada uma coleção de cadernos (07 volumes), com a finalidade de subsidiar os debates e reflexões e intensificar a mobilização.

${ }^{2}$ Nove municípios fazem parte da região do Alto Solimões, estado do Amazonas: Benjamin Constant, Atalaia do Norte, Tabatinga, São Paulo de Olivença, Amaturá, Santo Antônio do Içá, Tonantins, Jutaí e Fonte Boa.

3 Escolas que passaram por um processo de nucleação e que na região a denominam de escolas polos rurais. Geralmente são essas escolas que oferecem os anos finais do ensino fundamental e ensino médio.

${ }^{4}$ Professor do beiradão é um termo utilizado pela população local para se referir ao professor da cidade que atua na zona rural da região.

${ }^{5}$ Tipo de embarcação comum na região. São canoas com coberturas de lona ou zinco, com motor que varia de 9 a $13 \mathrm{HP}$.

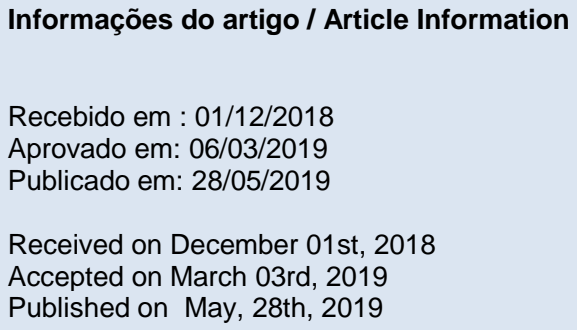

Contribuições no artigo: A autora foi a responsável por todas as etapas e resultados da pesquisa, a saber: elaboração, análise e interpretação dos dados; escrita e revisão do conteúdo do manuscrito e; aprovação da versão final a ser publicada.

Author Contributions: The author was responsible for the designing, delineating, analyzing and interpreting the data, production of the manuscript, critical revision of the content and approval of the final version to be published. 
Conflitos de interesse: A autora declarou não haver nenhum conflito de interesse referente a este artigo.

Conflict of Interest: None reported.

\section{Orcid}

Jarliane da Silva Ferreira

(iD) http://orcid.org/0000-0003-1180-789X

\section{Como citar este artigo / How to cite this article}

APA

Ferreira, J. S. (2019). O ensino em turmas multisseriadas e suas condições de trabalho: um olhar para as escolas do campo na região do Alto Solimões, Amazonas. Rev. Bras. Educ. Camp., 4, e6230. DOI: http://dx.doi.org/10.20873/uft.rbec.e6230

ABNT

FERREIRA, J. S. O ensino em turmas multisseriadas e suas condições de trabalho: um olhar para as escolas do campo na região do Alto Solimões, Amazonas. Rev. Bras. Educ. Camp., Tocantinópolis, v. 4, e6230, 2019. DOI: http://dx.doi.org/10.20873/uft.rbec.e6230 